\title{
Comparison of three Under-Frequency Load Shedding Schemes referring to the Power System of Sri Lanka
}

\author{
Tharangika Bambaravanage, Sisil Kumarawadu and Asanka Rodrigo
}

\begin{abstract}
To cater the consumers with high quality electricity, a reliable Power System (PS) is a must. Recently several major changes have been taken place in the PS of Sri Lanka. Today the PS of Sri Lanka, that operates under Ceylon Electricity Board (CEB) is comprised with 3 numbers of coal Power Plants (PPs), each having a generation capacity of $300 \mathrm{MW}$, a combined cycle PP (Yugadanavi) and considerably extended transmission network[1], [2]. To maintain the stability of a PS, the balance between power generation and consumption (demand) is a must. In any event, the first few seconds of frequency degradation and recovery after a major generator trip is essentially be accomplished by governor control. When the PS's self-regulation is insufficient to establish a stable state, the system frequency (SF) will continue to drop until it is arrested by automatic under-frequency load shedding (UFLS) to re-establish the load-generation balance within the time constraints necessary to avoid system collapse [3], [4]. Therefore it has become necessary to review the performance of the present CEB LS Scheme (LSS) and suggest amendments where necessary. This paper proposes two LSSs which can address the recent changes taken place in the Sri Lanka PS while maintaining stability. Having simulated the PS of Sri Lanka, performance comparison of the CEB LSS which is being implemented in Sri Lanka and the proposed LSSs (PLSSs) are presented. Results show that the LSS should exclusively be specific for a particular PS. It depends on factors such as electrical PS practice, regulations, largest generator capacity, electricity consumption pattern etc.
\end{abstract}

Keywords: $\quad$ PS, UFLS, Stability, Rate of Change of Frequency (ROCOF), Disintegration of PS.

\section{Introduction}

Reliable and secure operation of electrical PSs is of great importance and it has always been a primary goal for PS operators. But from time to time it has been reported that the PSs are exposed to serious disturbances[5], [6], [7].

Therefore, it is essential that the system be designed and operated so that more probable contingencies can be sustained without any losses of loads (except that is connected to the faulted element) and the most adverse possible contingencies do not result in uncontrolled, widespread and cascading power interruptions[5], [8]- [9].

A mismatch between generation and demand can lead to power system instability. This mismatch may be due to,

- Sudden increase of generation than the load if the power consumption is much less than the power generation, unless the Automatic Generation Control (AGC) System acts to rapidly reduce generation, there will be a critical situation which may even lead the system to a collapse of the entire generating system.

- Sudden deficit of generation than the load - if the electricity consumption is much higher than the power generation, unless the AGC system acts fast and produce more electricity, there will be an emergency situation, and a failure is possible.

- Hidden failures in protection systems[7],[9], [10].

In order to prevent this dramatic event, various LS strategies are adopted.

All of them are to shed a proper amount of load to decrease the overall power consumption and restore the power balance between generated and absorbed power. The problem of optimal LS has been extensively investigated and many publications on the utility implementation are presented in the literature over the past[5], [9][11].Selection of a suitable LS strategy depends on the application scenario.

Eng. (Mrs.) Tharangika Bambaravanage, M.Eng. (Moratuwa), B.Sc.Eng. (Moratuwa), C.Eng., MIE(Sri Lanka), MIEEE, Lecturer, Division of Electrical \& Electronics Engineering Technology, Institute of Technology, University of Moratuwa.

Eng. (Prof.) Sisil P. Kumarawadu, Ph.D.(Saga), M.Eng.(Saga), B.Sc.Eng.(Moratuwa), SMIEEE, Professor of Electrical Engineering, Department of Electrical Engineering, Faculty of Engineering, University of Moratuwa.

Eng. (Dr.) Asanka S. Rodrigo, Ph.D., M.Sc.(Eng), B.Sc.Eng.(Moratuwa), MIEE, AMIE(Sri Lanka), Senior Lecturer, Department of Electrical Engineering, Faculty of Engineering, University of Moratuwa. 
- In local PSs, detection of the location of the contingency is trivial. For such situations, LS actions are implemented mainly based on frequency and its derivatives.

- In large scale and wide area PSs, typically the adopted methods are based on voltage measurement. This helps in determining the perturbation location so that the area affected by the power deficiency can be addressed by implementing a LS action confined to that particular area[6], [9], [12].

A LSS acts whenever it identifies a situation of danger for the PS. The most initiative method of checking the level of danger is measuring the average frequency of the grid: when the frequency falls below a certain threshold it is possible to obtain an indication on the risk for the system and consequently to shed a certain amount of load. Although this approach is effective in preventing unintended LS in response to small disturbances with relatively longer time delays and low frequency thresholds, it is not capable of distinguishing the difference between normal oscillations and large disturbances in the power system. Thus, this approach is likely to shed lesser loads at large disturbances.

During a load and generation imbalance situation that occurred due to a generation deficiency, the amount of over-load is not known. Therefore the load is shed in blocks until the frequency stabilizes. Different methodologies have been introduced to implement LS actions based on frequency [5], [10], [11], [13]-[14]. With reference to them, it is possible to understand that an intelligent \& adaptive control and protection system for wide-area disturbance is needed to make full utilization of the power network possible, which will be less vulnerable to a major disturbance.

Adaptive setting of frequency and frequency derivative (ROCOF) relays, based on actual system conditions, may enable more effective and reliable implementation of LSSs[6], [12], [15].A major component of adaptive protection systems is their ability to adapt to changing system conditions. Thus, relays which are going to participate in the process of control and protection must necessarily be adaptive. In precise, this must be a relay system that allows communication with the outside word. These communication links must be secure and the possibility of their failure must be considered in designing the adaptive relays [12].

Figure 1 [16], introduced by Fink and Carlson explains the PS operating states. In this model, conventional protection and control is likely to be effective in the 'alert' and 'emergency' states where the load capacity and generating capacity are matched and unchanged. In the 'extreme' state, they are no longer matched and system integrity/reliability protection schemes are required [16]. The possibility of going for "disintegration of the PS of Sri Lanka" has been identified and discussed [17]. This requires a large capital investment to do the relevant modifications. Without doing much modification to the prevailing UFLSS, and utilizing the available resources, a new LSS is proposed in this paper. It has been showed through simulations that the proposed scheme is more effective compared to the prevailing one.

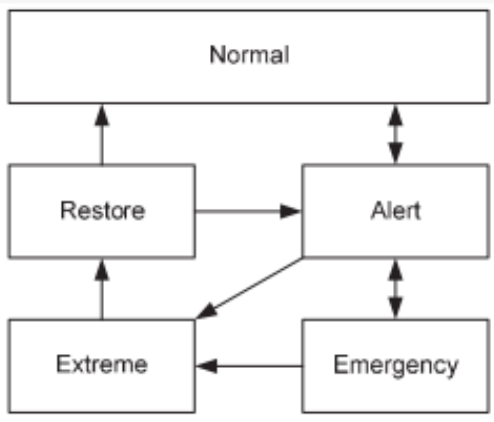

Figure 1 - Fink and Carlson model that explains the PS operation

\section{Identification of Parameters}

PS of Sri Lanka has a daily maximum power demand of around $2100 \mathrm{MW}$. This always takes place as the night peak of the load curve of the country. Out of the total electricity generation, about $65 \%$ is based on thermal and the majority of the balance is from hydro PPs. About 200 MW of the total generation is received from embedded generation which comprises with hydro and wind power [18]. 900 MW 'Lakwijaya' PP has the highest generation capacity in Sri Lanka[1]. It comprises with three 300 MW generators that operate on coal and possesses around $25 \%$ of the total installed capacity of Sri Lanka. Therefore it performs a very important role in economic aspects, since its unit cost of generation is much less compared to that of other thermal PPs. Hence if a failure occurs and if it happened to isolate it from the national grid, there will be a considerable impact on the PS stability that may lead to a brown out or a black-out situation [10]. On the other hand, with the increased penetration of intermittent renewable energy, power systems encounter a high possibility of uncertainty and 
variability causing generation and load imbalances. With the state-of-the-art wind forecasting methods, the hour ahead forecast errors for a single wind power plant are still around $10 \%-15 \%$ with respect to its actual outputs[19]. Mini-hydro PPs are designed with a plant factor of around $40 \%$ because of the uncertainty in power generation associated with it[20]. Thus, a well-designed UFLSS is critical to safe-guard the system during extreme situations to avoid complete system black-outs while maintaining its stability.

Table 1 gives the LSS that is being implemented in Sri Lanka.

Table1- Present Ceylon Electricity Board (CEB)LSS

\begin{tabular}{|c|c|}
\hline $\begin{array}{l}\text { Frequency } \\
\text { state }\end{array}$ & Time delay and magnitude of LS \\
\hline $\mathrm{f} \geq 48.75 \mathrm{~Hz}$ & No load shed \\
\hline $\mathrm{f}<48.75 \mathrm{~Hz}$ & $\begin{array}{l}\text { Step 1: } 6.5 \% \text { of load } \\
100 \mathrm{~ms} \text { time delay }\end{array}$ \\
\hline $\mathrm{f}<48.5 \mathrm{~Hz}$ & $\begin{array}{l}\text { Step 2: } 6.5 \% \text { of load } \\
500 \mathrm{~ms} \text { time delay }\end{array}$ \\
\hline $\mathrm{f}<48.25 \mathrm{~Hz}$ & $\begin{array}{l}\text { Step 3: } 12 \% \text { of load } \\
500 \mathrm{~ms} \text { time delay }\end{array}$ \\
\hline $\mathrm{f}<48 \mathrm{~Hz}$ & $\begin{array}{l}\text { Step 4: } 9 \%+3.5 \% *=12.5 \% \text { of load } \\
500 \text { ms time delay }\end{array}$ \\
\hline $\mathrm{f}<47.5 \mathrm{~Hz}$ & $\begin{array}{l}\text { Step } 5: 3 \%+4.5 \% *=7.5 \% \text { of load } \\
\text { Instantaneous }\end{array}$ \\
\hline $\begin{array}{c}\mathrm{f}<49.0 \mathrm{~Hz} \\
\& \\
-0.85<\mathrm{df} / \mathrm{dt}\end{array}$ & $\begin{array}{l}13 \%+3.5 \%^{*}+4.5 \% *=21 \% \text { of load, } \\
100 \mathrm{~ms} \text { time delay }\end{array}$ \\
\hline
\end{tabular}

According to the PS regulations and practice of Sri Lanka[21], it has been identified that:

- Voltages at the live bus-bars of CEB network: $220 \mathrm{kV} \pm 5 \%$ $132 \mathrm{kV}- \pm 10 \%$

- System frequency (SF):

Normal operating range : $50 \mathrm{~Hz} \pm 1 \%$

- According to the current practice of CEB,

Normal operating range: $50 \mathrm{~Hz} \pm 4 \%$

Short term variations : $-6 \%$ to $+5 \%$ up to 3 s.

\section{A Identifying setting frequency:}

Rotating machineries are designed for their optimum performance at a specific frequency here this paper considers that as $50 \mathrm{~Hz}$ operation. For the safe and effective operation of generators, frequency should not go below few percent of the rated frequency. Continuous operation of steam turbines should be restricted to frequencies above 0.99 p.u., (for $50 \mathrm{~Hz}$ base it is $49.5 \mathrm{~Hz}$ ). Operation below $49.5 \mathrm{~Hz}$ should be limited to very short durations. Hence it is very important to co-ordinate the settling frequency of the PS and the relay tripping frequency in use to control generator shut-down [9], [11], [16].
In order to improve the quality of power, it has been considered that the PS of Sri Lanka should have a rated frequency of $50 \mathrm{~Hz}$ with below tolerances under the given conditions. The normal operating range has been considered as the settling frequency range during the steady state operation after a disturbance.

- SF - Normal operating range : $50 \mathrm{~Hz} \pm 1 \%$

- SF - During an emergency/transient : $50 \mathrm{~Hz}$ $\pm 4 \%$

Short term variations : $-6 \%$ to $+5 \%$ up to 3 s.

\section{$B$ Deciding the number of steps in the LSS:}

It is very important to decide a correct number of LS steps as it may cause over shedding for a small disturbance or less severe over-load. As a solution it can be considered to increase the number of steps and divide the load among them. Proper co-ordination among steps is equally important.

- Currently PS of Sri Lanka comprises 6 no. of stages in its LSS.

- In [11]and[22]it has been mentioned that '3-5 steps' is the most adequate selection based on experience.

- In [23] a comparison of several UFLSSs has been carried out which were with different number of stages (e.g. 6, 8 and more than 8 number of stages).

Therefore for this proposed LSS, it has been considered the step size as six.

\section{First step of LS scheme:}

With reference to the present LSS of SL, it initiates its LS action at a frequency of $48.74 \mathrm{~Hz}$. This is a value that is far below the system normal operating range. Many utilities that operate with a rated frequency of $60 \mathrm{~Hz}$ set the first step of LS at $59.5 \mathrm{~Hz}$ [22]. That is,

The $1^{\text {st }}$ occurs at $59.5 / 60=0.99$ p.u.

With $50 \mathrm{~Hz}$ base frequency,

$$
\text { The first step } \quad=0.99 \times 50=49.5 \mathrm{~Hz}
$$

But, PS of Sri Lanka's normal operating frequency $(f)$ range is, $50.5>f>49.5 \mathrm{~Hz}$. Hence, $49.4 \mathrm{~Hz}$ is a better option for the first step of the LSS. Further, Initial under-frequency load shedding relay settings are typically $59.3 \mathrm{~Hz}$ in the U.S. systems [3]. For such situations,

The 1st occurs at 59.3/60 = 0.988 p.u.

With $50 \mathrm{~Hz}$ base frequency,

$$
\text { The first step } \quad=0.988 \times 50=49.4 \mathrm{~Hz}
$$


In [22] it has been justified for a PS operating at $60 \mathrm{~Hz}$ can have a LSS with first step as $59.5 \mathrm{~Hz}$. The same arguments referring to a SF of $50 \mathrm{~Hz}$ can be considered as below.

- All of the larger turbine generators on the system are not rated for continuous generation below 0.99 p.u. (for $60 \mathrm{~Hz}$ it is 59.5 $\mathrm{Hz}$ ) depending on the manufacturer. Thus setting the initial LS frequency at a relatively high value, such as $49.4 \mathrm{~Hz}$ (for $50 \mathrm{~Hz}$ PS), also tends to limit the maximum frequency deviation.

- A LS program starting at $49.4 \mathrm{~Hz}$ can be more effective in minimizing the depth of the UF response for a heavy over load than would a similar program which has a lower $1^{\text {st }}$ shedding frequency.

- Hence for a $50 \mathrm{~Hz}$ PS, it has been argued and decided to consider the first step of the UFLSS as $49.4 \mathrm{~Hz}$, (instead of considering $48.75 \mathrm{~Hz}$ ).

\section{$D$ Identifying when to implement LS based on ROCOF:}

According to the present CEB scheme,

If $\mathrm{ROCOF}<-0.85 \mathrm{~Hz} / \mathrm{s}$ and $\mathrm{SF}=49 \mathrm{~Hz}$, a $20 \%$ of the load is to be shed. But, practical as well as simulation results show that the maximum ROCOF occurs at an instant after about 1.5-1.6 s from the moment of generation deficiency occurs. If we assume that the disturbance occurs at a SF of $49.5 \mathrm{~Hz}$ and this disturbance tend to cause a $\mathrm{ROCOF}=-0.85 \mathrm{~Hz} / \mathrm{s}$, simulation results show that the time consumed to achieve a frequency of $49 \mathrm{~Hz}$ is much less than $1.5 \mathrm{~s}$. So the response corresponding to the conditions " $\mathrm{f}$ $<49.0 \mathrm{~Hz} \& \quad-0.85<\mathrm{df} / \mathrm{dt}^{\prime}$ of the CEB scheme occurs with much delay. Since this may lead to initiate initial stages of the current CEB LSS, there is a high chance of shedding an excessive amount of load (Section V of CEB LSS discusses this further).

\section{E Delay Time (DT):}

The DT may vary from one LSS to another. But according to [11], the total amount of time necessary to clear the load can be considered as,

$$
\begin{array}{cl}
\mathrm{TD}=\mathrm{R}_{\mathrm{OT}}+\mathrm{T}_{\text {Intentional }}+\mathrm{B}_{\mathrm{OT}} & \\
\begin{array}{cl}
\text { Where, } \mathrm{TD} & =\text { total clearing time } \\
\mathrm{R}_{\mathrm{OT}} & =\text { relay operating time } \\
\mathrm{T}_{\text {Intentional }} & =\text { intentional time delay (as a } \\
\mathrm{B}_{\mathrm{OT}} & =\mathrm{CB} \text { operating time }
\end{array}
\end{array}
$$

PS of Sri Lanka uses a $T_{\text {Intentional }}$ of $0.1 \mathrm{~s}$ for its $1^{\text {st }}$ step and $0.5 \mathrm{~s}$ for $2^{\text {nd }}$ to $4^{\text {th }}$ steps. The condition " $\mathrm{f}$ $<49.0 \mathrm{~Hz} \&-0.85<\mathrm{df} / \mathrm{dt}^{\prime}$, which is adaptive, operates with a $\mathrm{T}_{\text {Intentional }}$ of $0.1 \mathrm{~s}$. Its $5^{\text {th }}$ step gets initiated with $\mathrm{T}_{\text {Intentional }}=0 \mathrm{~s}$.
- Chin-Chyr Huang et al suggest a TD of $0.1 \mathrm{~s}$ for the UFLS simulation, but states it is not necessary to have the same time interval for each step[22].

- Quamrul Ahsan et al used a time delay of 7.5 cycles $\simeq 0.15 \mathrm{~s}$ (with a $50 \mathrm{~Hz}$ system) to implement $2^{\text {nd }}$ and $3^{\text {rd }}$ steps in their UFLS simulation program [5].

Further, referring to equation(1)and considering the following approximated values,

$$
\begin{aligned}
\mathrm{TD} & =\mathrm{R}_{\mathrm{OT}}+\mathrm{T}_{\text {Intentional }}+\mathrm{B}_{\mathrm{OT}} \\
& \simeq 0.2 \mathrm{~s}
\end{aligned}
$$

Where,

$\mathrm{R}_{\mathrm{OT}} \simeq 60 \mathrm{~ms}, \mathrm{~B}_{\mathrm{OT}} \simeq 83 \mathrm{~ms}[16],[24]$ and $\mathrm{T}_{\text {Intentional }} \simeq 60$ $\mathrm{ms}$ (three nos. cycles). Hence for these PLSS simulations, a TD of $0.2 \mathrm{~s}$ was considered.

Since it is evident that Relays and CB take few milliseconds to get operated during a faulty situation, that time should also be included in the simulation program of the Present CEB LSS. The flow chart shown in Figure 2 demonstrates

\begin{tabular}{|c|c|}
\hline $\begin{array}{c}\text { Frequency } \\
\text { state }\end{array}$ & $\begin{array}{c}\text { Actual Delay Time considering } \\
\text { the relay and circuit breaker } \\
\text { operation }\end{array}$ \\
\hline $\mathrm{f} \geq 48.75 \mathrm{~Hz}$ & No load shed \\
\hline $\mathrm{f}<48.75 \mathrm{~Hz}$ & Step 1: $100 \mathrm{~ms}+140 \mathrm{~ms}=0.24 \mathrm{~s}$ \\
\hline $\mathrm{f}<48.5 \mathrm{~Hz}$ & Step 2: $500 \mathrm{~ms}+140 \mathrm{~ms}=0.64 \mathrm{~s}$ \\
\hline $\mathrm{f}<48.25 \mathrm{~Hz}$ & Step 3: $500 \mathrm{~ms}+140 \mathrm{~ms}=0.64 \mathrm{~s}$ \\
\hline $\mathrm{f}<48 \mathrm{~Hz}$ & Step 4: $500 \mathrm{~ms}+140 \mathrm{~ms}=0.64 \mathrm{~s}$ \\
\hline $\mathrm{f}<47.5 \mathrm{~Hz}$ & Step 5: $140 \mathrm{~ms}=0.14 \mathrm{~s}$ \\
\hline $\begin{array}{c}\mathrm{f}<49.0 \mathrm{~Hz} \\
\& \\
-0.85<\mathrm{df} / \mathrm{dt}\end{array}$ & $100 \mathrm{~ms}+140 \mathrm{~ms}=0.24 \mathrm{~s}$ \\
\hline
\end{tabular}
the Actual LSS considering the time factor $\left(\mathrm{R}_{\mathrm{TO}}+\mathrm{B}_{\mathrm{OT}} \simeq 140 \mathrm{~ms}\right)$ involved in each LS stage.Table2 shows the calculation of actual delay time involved in each load shedding action.

Table2 - Time delays corresponding to each LS action in the simulated present CEB LSS.

\section{Proposed Methodologies of Load Shedding}

\section{A LSS -I (Based on prevailing facilities with the} $C E B)$ :

$54 \%$ of the prevailing load is involved in the LSS. It is comprised with 6 nos. of shedding stages that get operated based on SF and ROCOF of the PS. Figure 3 demonstrates a flow chart of the proposed LSS. The SF and its $1^{\text {st }}$ derivative is measured all throughout. If the $\mathrm{SF}$ goes below the rated conditions given in section II, power system instability situation may be possible. 


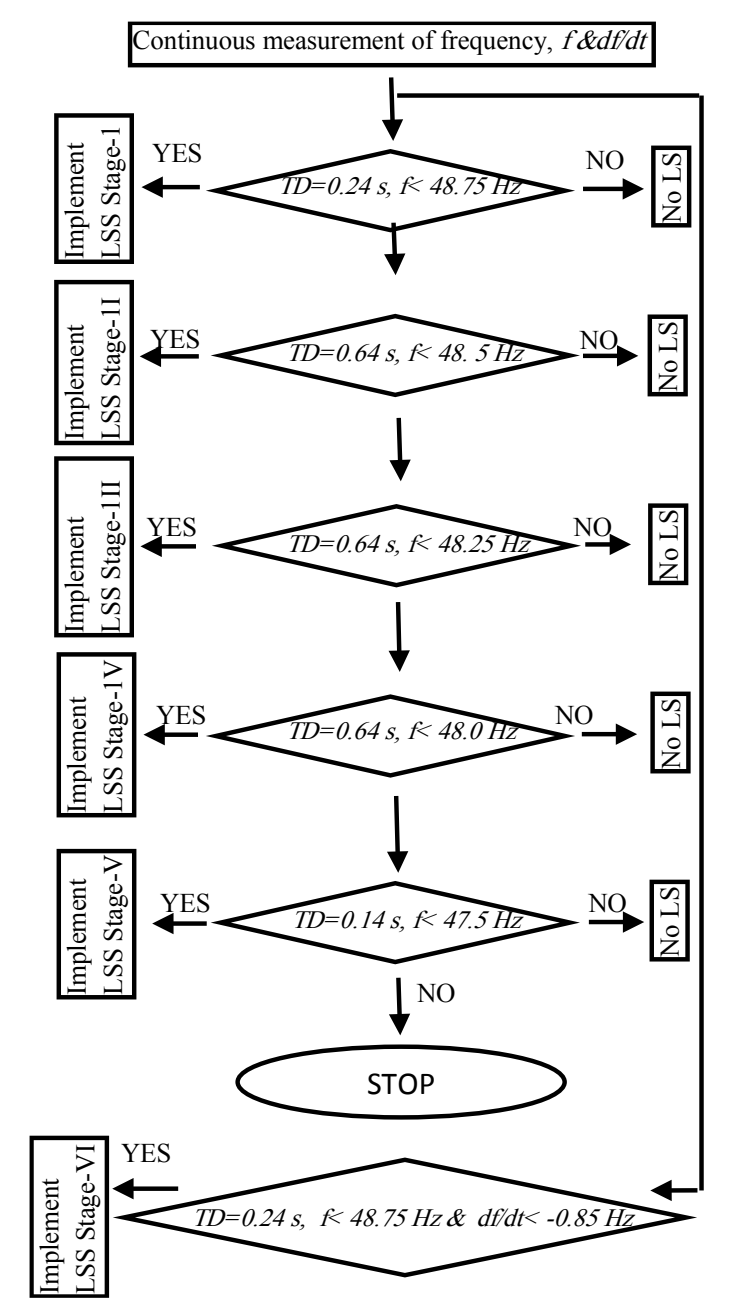

Figure 2- Flow chart of the simulated present CEB LSS which comprises with 6 nos. of stages.

When actual SF variation against time as well as simulation results are analyzed, it is evident that usually, the PS reaches its $\mathrm{df} / \mathrm{dt}$ a maximum after about $1.5-1.6 \mathrm{~s}$ from the instant of the occurrence of the disturbance. To initiate the LSS, the system frequency should be dropped to a frequency of $49.4 \mathrm{~Hz}$. From 1-2 and 3-4 LS stages, $6 \%$ and $8 \%$ of the prevailing load is shed respectively, based on the SF. At the $5^{\text {th }}$ stage, the LSS is more adaptive to the system behavior as it gets implemented based on the ROCHOF of the PS, which is $10 \%$ load is scheduled to be shed at $-0.675 .5 \mathrm{~Hz} / \mathrm{s}$. The $6^{\text {th }}$ stage is once again based on a combination of SF as well as ROCOF with a load size of $10 \%$. The $6^{\text {th }}$ or the last stage gets implemented when the PS satisfies both the conditions $\mathrm{df} / \mathrm{dt} \leq-0.95 \mathrm{~Hz} / \mathrm{s} \& \mathrm{SF}=48.6 \mathrm{~Hz}$. This amounts to $21 \%$ of the total load. With the implementation of the $6^{\text {th }}$ stage, a $59 \%$ of the total prevailing load is scheduled to be shed. It is possible to decide which loads are to be shed, considering such factors as their importance to communities (e.g. hospitals), contribution to national economy (e.g. industrial zones) etc. It is very important to limit the SF reducing below0.95 p.u. (57 Hz and $47.5 \mathrm{~Hz}$ for $60 \mathrm{~Hz}$ and $50 \mathrm{~Hz}$ PSs respectively). It may lead the PS unstable further due to tripping of steam turbine and gas turbine PPs [9].This can badly affect the performance of induction motors in operation, which in turn gives negative effects on the national economy as well. For a PS majorly based on thermal-plants it may cause a system brown out or even a black out.

\section{B LSS - II (with Disintegration of the PS)}

The uninterrupted power supply load (critical load segment) is designated as $40 \%$ of the total load. The LSS is comprised with 2 nos. of stages, named Phase - I and Phase - II. During Phase I, approximately $30 \%$ of the prevailing load is shed to maintain the stability. Disintegration of the PS is occurred under the Phase - II.

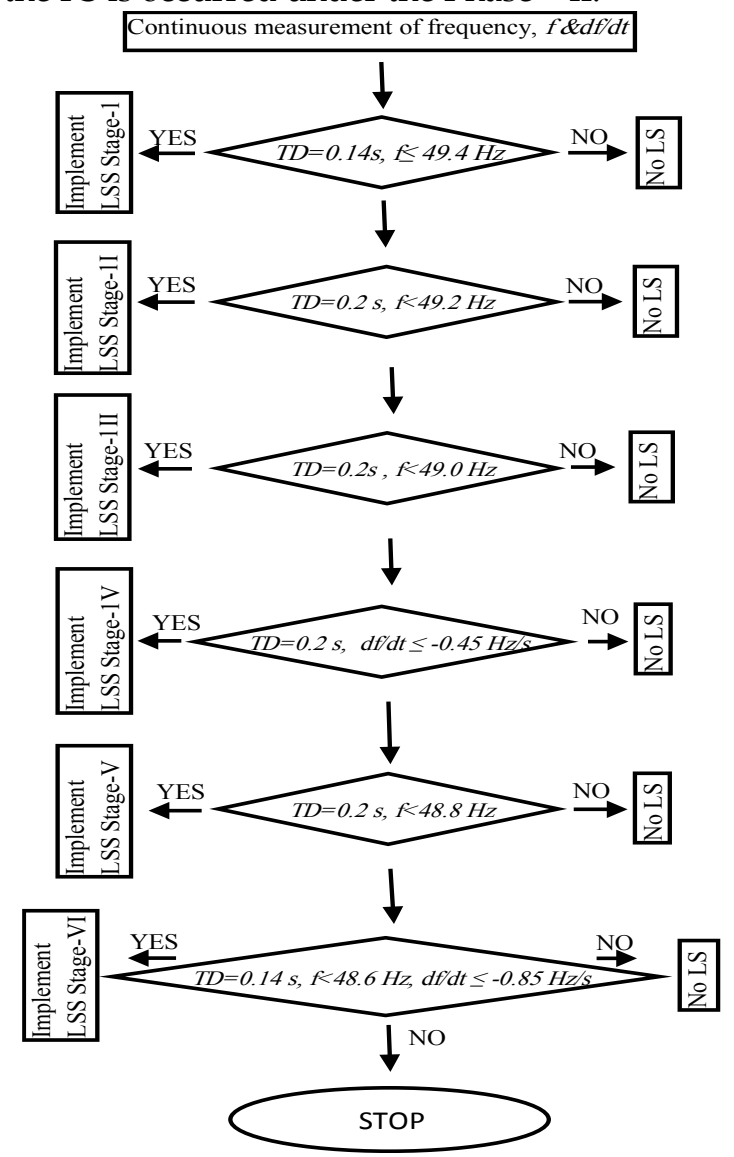

Figure 3- Flow chart of the LSS-I comprised with 6 nos. of stages.

If the PS cannot be brought to a stable operating condition with Phase - I of the LSS, then the islanding operation is done. The Phase - II gets initiated if the SF reaches $48.6 \mathrm{~Hz}$. It can be proved that if LS stages get implemented above $48.6 \mathrm{~Hz}$ and if the amount of load shed is sufficient to make the system stable, then the SF can be maintained above $47 \mathrm{~Hz}$ (closer to 47.5 $\mathrm{Hz}$ ), which is the safe operating frequency for 
steam PPs. As the disintegration of the PS is done at $48.6 \mathrm{~Hz}$, the National Grid's as well as the islands' stable operation is much assured.

To initiate the LSS, the system frequency should be dropped to $49.4 \mathrm{~Hz}$. Figure 4 demonstrates the Phase - I of the LSS-II: from 1-2, 3 and 4 LS stages, $6 \%, 8 \%$ and $10 \%$ of the prevailing load is shed respectively, based on the SF. This is approximately comprised of $30 \%$ of the total (prevailing) system load. The $5^{\text {th }}$ stage is for the disintegration of the PS. Four possible locations in PS of Sri Lanka were identified as load centres that can be operated as islands.

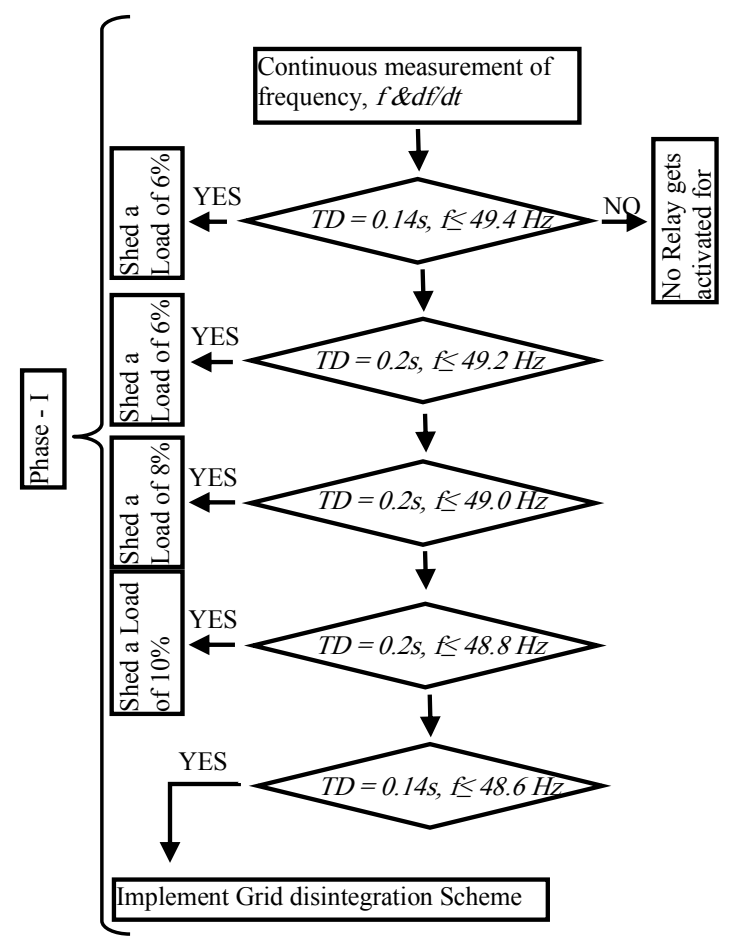

Figure 4- Flow chart of the Phase-I of LSS-II which initiates Islanding at $\mathrm{SF}=48.6 \mathrm{~Hz}$.

Boundaries of those locations suitable for Islanding are:

- Island Matugama (the load fed from Pannipitiya grid - Loads connected to Panadura, Horana, Matugama and Ambalangoda Bus-bars (BB))

- Island Samanalawewa (the load fed from Balangoda grid - Loads connected to Ratnapura, Embilipitiya, Hambantota, Deniyaya, Galle, Beliatta and Matara BB)

- Island Rantembe (the load fed from Rantembe grid - Loads connected to NuwaraEliya, Badulla, Inginiyagala and Ampara BB)

- Island Kiribathkumbura (the load fed from Anuradhapura \& New-Anuradhepura grids Loads connected to Vavuniya, Kilinochchi,
Trincomalee, Habarana, Valaichchenai, Ukuwela, Bowatenna and Kiribathkumbura $\mathrm{BB})$

After the controlled disintegration of the national grid, the frequency and voltage responses of all four islands and the national grid were observed. They all were within specified limits. Figure 5 demonstrates the sequential steps that correspond to 'IslandRantembe' which operates as an island in the Phase-II of the proposed LS scheme. Total generation within the Island-Rantembe at the instant of disintegration of the PS is 24.17 MW. Power in demand at that instant is 66.3 MW. Thus, the excess demand is $42.13 \mathrm{MW}$.

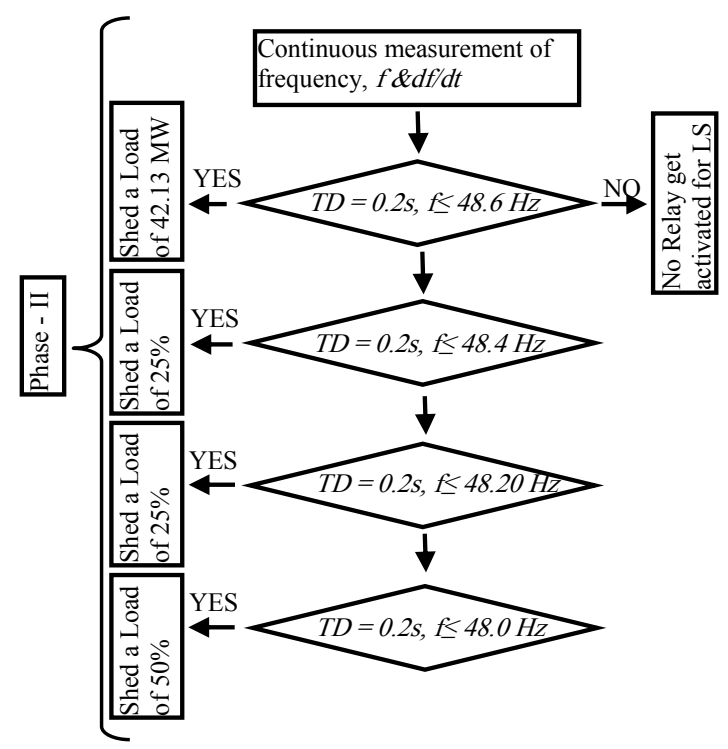

Figure 5- Flow chart of the Phase-II of LSS-II that corresponds to Island-Rantembe. The implementation of the no. of LS stages is sequential and specific to this Island-Rantembe.

The Phase-II of the proposed scheme is implemented sequentially. The amount of load that involves in the LSS is $10 \%(24.7 \times 10 \%=2.47$ $\mathrm{MW})$ of the available generation. Out of this $10 \%$, the LSS gets implemented with $25 \%, 25 \%$, and $50 \%$ in stages 1,2 and 3 respectively. The activation of the number of steps totally depends on the state of the island.

\section{Results and Discussion}

The LS schemes described in Section II (CEB LSS) and Section III (PLSSs) were simulated in the PS of Sri Lanka. Different scenarios of generation deficits were considered to observe the frequency and voltage responses of the schemes. Each scenario was applied to all three schemes and several such scenarios were considered. Generation deficits were originated by forcing capacity outages and corresponding 
frequency variations occurred for the LSSs are tabulated as shown in Table 3 for comparison. The observations were received from a PS simulation done for a load flow with actual data, received from the CEB. A model of the PS of Sri Lanka was simulated using the software PSCAD EMTDC. At that instant the total generation was $1637 \mathrm{MW}$. The results discussed here are based on the above total generation.

With the results obtained in this simulation, it is evident that a LS step which gets implemented after $48.6 \mathrm{~Hz}$ can lead to situations where SF goes below $47.5 \mathrm{~Hz}$. This can also lead to instability situations in the PS.

- In the CEB LSS, the adaptive LS step (amounts to $21 \%$ of the total load) is to get implemented at $\mathrm{df} / \mathrm{dt} \leq 0.85 \mathrm{~Hz} / \mathrm{s} \& \mathrm{SF}=49.0 \mathrm{~Hz}$. As the maximum ROCOF occurs after about $1.5 \mathrm{~s}$ from the instant of the initiation of the disturbance, for such a large disturbance this $0.85 \mathrm{~Hz} / \mathrm{s}$ is achieved after $48.6 \mathrm{~Hz}$. Before reaching this state, possibility of implementing earlier steps can lead to excessive LS. Hence the effectiveness of the LS step is questionable.

- The LSS itself has a step (5 $5^{\text {th }}$ step) with the condition for implementing if frequency < $47.5 \mathrm{~Hz}$ with no intentional time delay. Even if that step gets implemented, the PS takes further time to bring the SF above $47.5 \mathrm{~Hz}$. In Sri Lanka, thermal PPs contribute to a considerable portion of power generation, which is $\simeq 65 \%$ of its average total generation. Hence it has a large tendency to collapse the whole PS with the available LSS.

- The CEB LSS helps to maintain the stability of the PS only at certain amounts of generation deficits. The frequency profile with $275 \mathrm{MW}$ capacity outage, corresponding to tripping of Lakvijaya Coal PP (one generator - since each generator contributes the PS with $275 \mathrm{MW}$ constant power), clearly shows that the system becomes stable with the current LSS. But if 2 nos. or 3 nos. coal PPs get tripped that may lead even to a catastrophic failure.

- Therefore it is very important to go for a LSS which does not lead the system frequency below the minimum allowable operating frequency $(47.5 \mathrm{~Hz})$ as well as that does not shed excessive load.

- The PLSSs supports the PS during generation deficits due to tripping of small generators as well as large capacity PPs (eg. Lakvijaya Coal PP-1, PP-2, PP-3 or any combination of these).

- The LSS - I can be implemented with the prevailing facilities in the PS of Sri Lanka. This suggests a better solution for the stability problem due to generation deficit.

- If the generation capacity increases further with large generators and with fluctuating generation capacities, it is a good option to go for disintegration of the power system. This let more consumers have electricity with less interruptions. This is demonstrated in the LSS - II. Even though it suggests $40 \%$ of the load to give priority in catering electricity (when concern the national grid, further amount of load receives power due to islanding operation.

\section{Conclusions}

The results show that the PLSSs are better solutions for the PS stability problem during generation deficiencies. These PLSSs are exclusively specific for the PS of Sri Lanka. It depends on the electrical PS practice, regulations, largest generator capacity, electricity consumption pattern, capacity of embedded generation etc.

- By implementing a LSS at an Initial stage of a generation deficiency, further reduction of SF can be eliminated.

- The chance of occurring the conditions " $\mathrm{f}<$ $49.0 \mathrm{~Hz}$ " \& ${ }^{\prime \prime}-0.85<\mathrm{df} / \mathrm{dt}^{\prime \prime}$ (which is adaptive to the system behavior)together, that are given in the CEB LSS is very much less. Hence there is a high chance to initiate earlier stages in addition to this stage, which may lead to overshedding.

- If it is possible to stop implementing the LSS at a system frequency of $48.6 \mathrm{~Hz}$, the PS can be retained within the specified frequency limits: i. e. the SF above $47 \mathrm{~Hz}$.

- Further by implementing disintegration of the national grid at an instant where the $\mathrm{SF}=48.6$ $\mathrm{Hz}$, rather than considering a specific $\mathrm{df} / \mathrm{dt}$ value, it is possible to retain the frequencies in islands above $47.5 \mathrm{~Hz}$. 


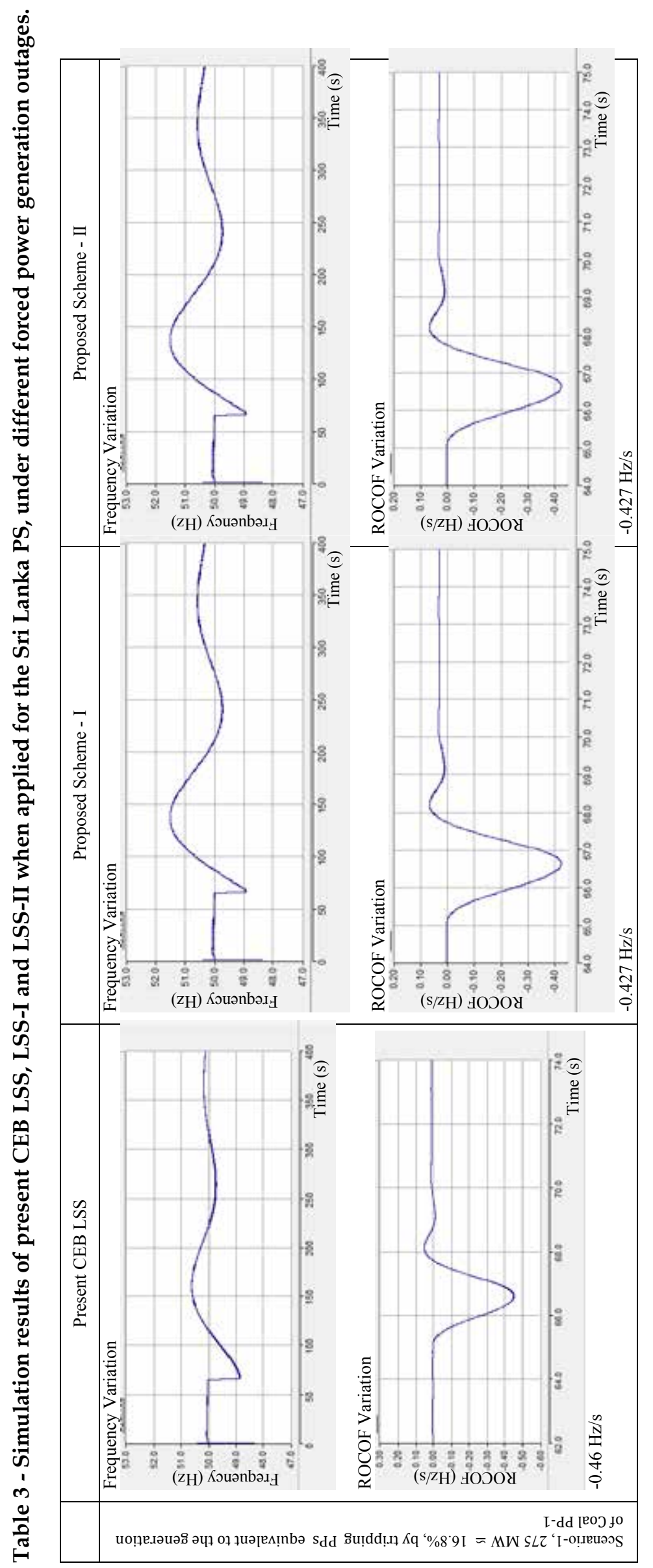



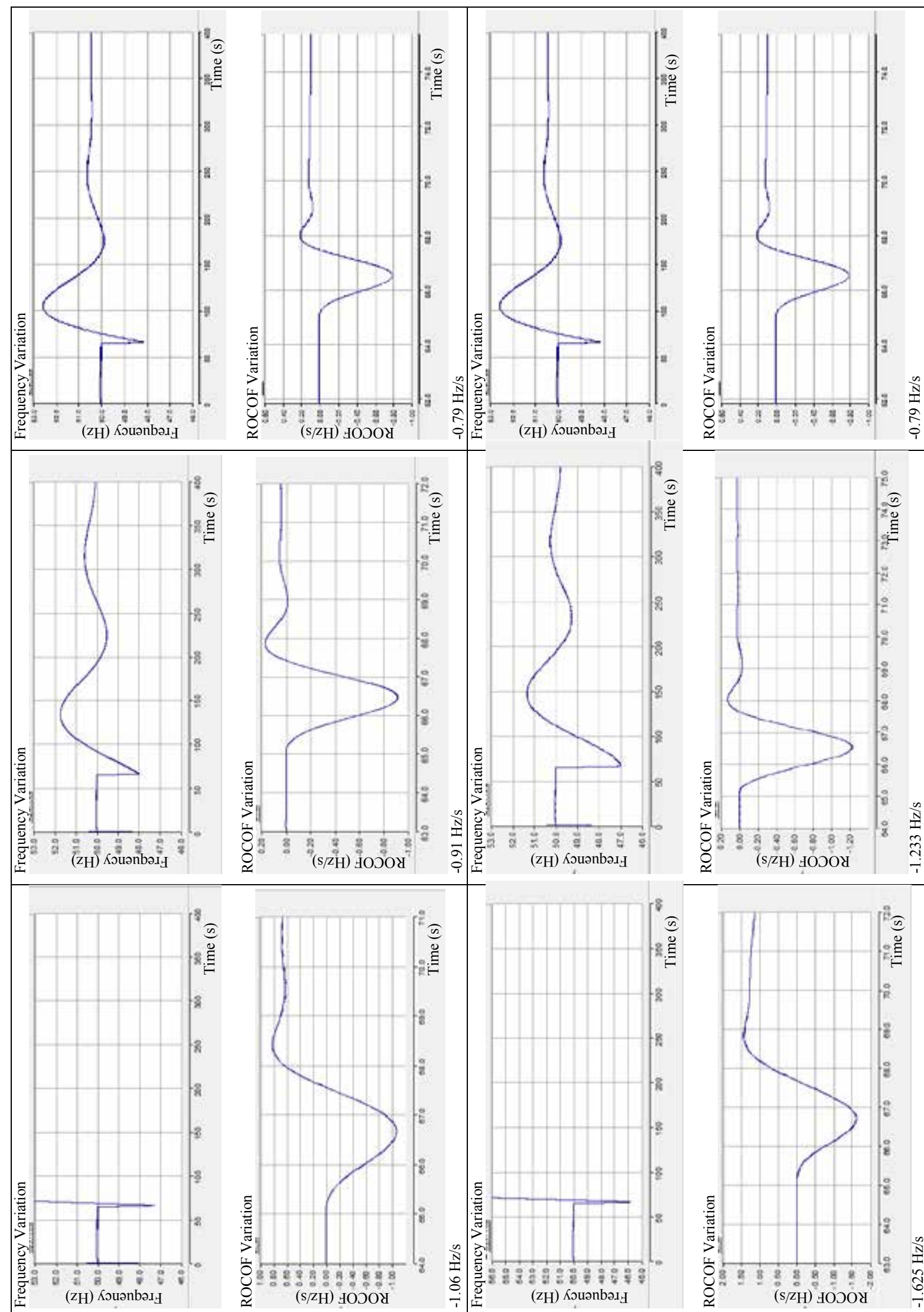

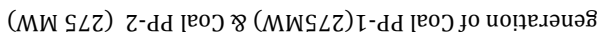

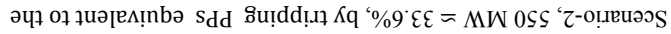




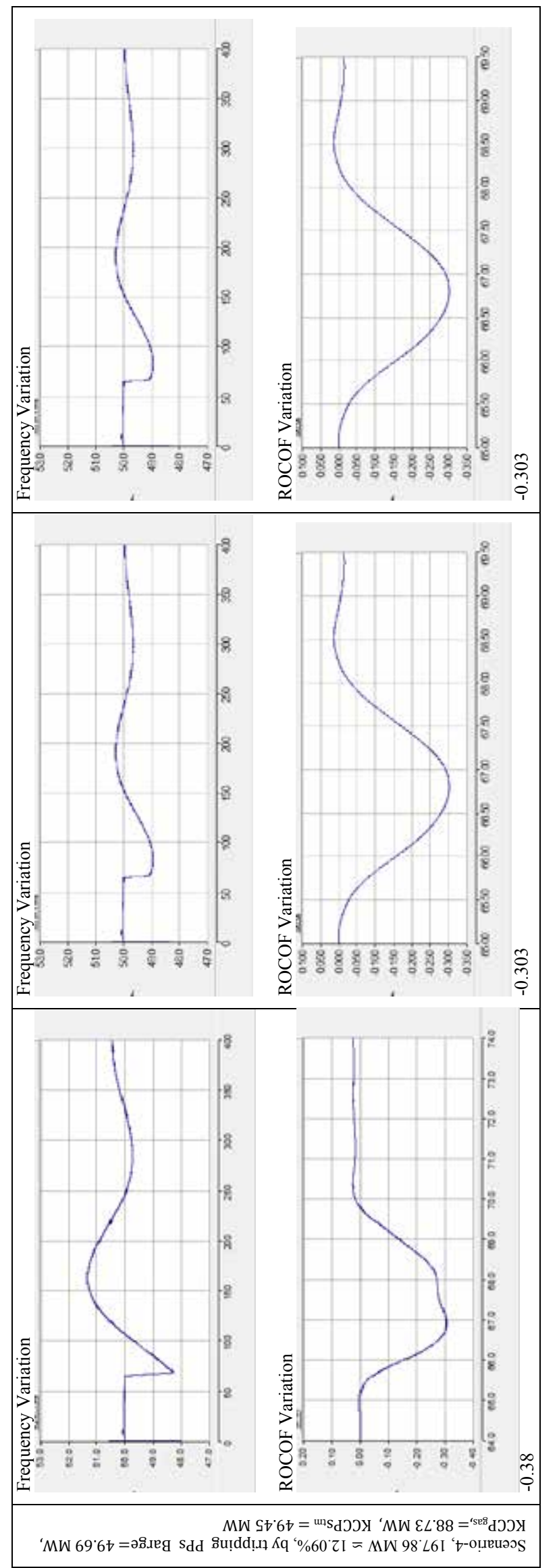




\section{Acknowledgement}

The Institute of Technology, University of Moratuwa (UOM) for Research Funding, the Department of Electrical Engineering, UOM for providing resources and facilitating the research, Dr. (Miss) N. W. A. Lidula concerning the Power System simulation, System Control Centre of the CEB for the information provided regarding the Sri Lanka power system operation are greatly acknowledged with many thanks.

\section{References}

[1] PUCSL, "Generation Performance in Sri Lanaka 2014," Public Utilities Commision of Sri Lanka, 2014.

[2] CEB, "Long Term Generation Expansion Plan 2015 - 2034," Ceylon Electricity Board, July 2015.

[3] Eremia, M., and Shahidehpour, M., Handbook of Electrical Power System Dynamics: modeling, stability \& control, IEEE press, Wiley, 2013.

[4] Saccomanno,F., Electric Power Systems, Analysis and Control, IEEE press, Wiley Interscience, 2003.

[5] Ahsan, M. Q., Chowdhury, A. H., Ahmed, S. S., Bhuyan, I. H., Haque, M. A., and Rahman, H., "Technique to Develop Auto Load Shedding and Islanding Scheme to Prevent Power System Blackout," IEEE transactions on Power Systems, vol. 27, no. No. 1, pp. 198-205, 2012.

[6] Giroletti, M., Farina, M., and Scattolini,R., "A Hybrid Frequency/Power Based Method for Industrial Load Shedding," Elsevier International Journal of Electrical Power and Energy Systems, no. 35, pp. 194-200, 2012.

[7] PUCSL, "Investigation Report on Power System Failures on 9th October 2009," Public Utilities Commision of Sri Lanka, 2010 February.

[8] Kundur, P., Power System Stability and Control, New York: McGraw-Hill, Inc., 1993.

[9] Barkans, J., and Zalostiba, D., Protection Against Black-outs and Self-restoration of Power Systems, Riga: RTU Publishing House, 2009.

[10] Bambaravanage, T., Rodrigo, A., Kumarawadu, S., and Lidula, N. W. A., "Under-Frequency Load Shedding for Power Systems with High Variability and Uncertainty," in ISPCC 2013 Proceedings of the IEEE international confrrence on Signal Processing, Computing and Control, Solan, India, 2013.

[11] Jones, J. R., and Kirkland, W. D., "Computer Algorithm for selection of frequency relays for Load Shedding," IEEE Computer Applications in Power, vol. 1, no. No. 1, pp. 21-25, 1988.

[12] Begovic, M., Novose, D., Karlsson, D., Henville,
C., and Michel, G., "Wide-Area Protection and Emergency Control," Proceedings of the IEEE, vol. 93, no. No. 5, pp. 876-891, May, 2005.

[13] You, H., Vittal, V., Jung, J., Liu, C., Amin, M., and Adapa, R., "An Intelligent Adaptive Load Shedding Scheme," in 14th PSCC, Sevilla, Spain, 24-28 June, 2002.

[14] Gunawardena, M., Hapuarachchi, C., Haputhanthri, D., and Harshana, I., "Capacity Limit of the Single Largest Generator uni, to Maintain Power System Stability through a Load Shedding Program," Department of Electrical Engineering, University of Moratuwa, December 2011.

[15] Bentarzi, H., Quadi, A., Ghout, N., Maamri, F., and Mastorakis, N. E., "A New Approach Applied to Adaptive Centralized Load Shedding Scheme," in CSECS'09 Proceedings of the 8th WSEAS International Conference on Circuits, systems, electronics, control $\mathcal{E}$ signal processing, Wisconsin, USA, 2009.

[16] Network Protection \&Automation Guide: Protective Relays, Measurements \& Control, Alstom Grid, May, 2011.

[17] Bambaravanage, T., Rodrigo, S. K. A., and Lidula, N. W. A., "A New Scheme of Under Frequency Load Shedding and Islanding Operation," Annual Transactions of IESL, Vols. vol. 1 - Part B,, pp. 290-296, 2013.

[18] CEB, "Long Term Transmision Development Plan 2011 - 2020,"Ceylon Electricity Board, July, 2011.

[19] Liang, J., Venayagamoorthy,G., andHarley, R., "Wide-Area Measurement Based Dynamic Stochastic Optimal Power Flow Control for Smart Grids With High Variability and Uncertainty," IEEEE transactions on smart grid, vol. 3, no. No. 1, pp. 59-69, March, 2012.

[20] Mahat, P., Chen, Z., and Bak-Jensen, B., "Control and Operation of distributed generation in distribution systems," ScienceDirect, Electric Power Systems research, vol. 81, pp. pp. 495-502, 2011.

[21] CEB, "Generator Interconnection of Sri Lanka," Ceylon Electricity Board.

[22] Huang,C., and Huang,S., "A Time-Based Load Shedding Protection for Isolated Power Systems," Electric Power Systems Research, no. 52, pp. 161-169, 1999.

[23] Delfino, B., Massucco, S., Morini, A., Scalera, P., and Silvestro, F., "Implementation and Comparison of Different under Frequency Load-Shedding Schemes," IEEE Power Engineering Society summer meeting, pp. 307-312, 2001.

[24] SIEMENS, SIPROTEC Over Current Time Protection 7SJ80; V4.6 manual., SIEMENS.

[25] Machowski, J., Bialek, J. W., and Bumby, J. R., Power System Dynamics, Stability and Control, John Wiley \& Sons, Ltd., 2008. 
[26] Wong, K., and Lau, B., "Algorithm for LoadShedding Operations in Reduced Generation Periods," IEE proceedings, vol. 139, no. No. 6, pp. 478-490, November, 1992.

[27] ABB, Load Shedding Controller, PML630 Product Guide, Vaasa, Finland: ABB, 2011.

[28] Mahat, P., Chen, Z., and Bak-Jensen, B., "Underfrequency Load Shedding for an Islanded Distribution System with Distributed Generators," IEEE transactions on Power Delivery, vol. 25, no. No. 2, pp. 911-918, April, 2010.

[29] Ford, J., Bevrani, H., and Ledwich, G., "Adaptive Load Shedding and Regional Protection," Elsevier International Journal of Electrical Power and Energy Systems, no. 31, pp. 611-618, 2009.

[30] Arnborg, S., Andersson, G., Hill, D. J., and Hiskens, I. A., "On Undervoltage Loadshedding in Power Systems," Electrical Power Systems, Elsevier Science Ltd., vol. 19, no. No. 2, pp. 141149, 1997.

[31] Maliszewski, R., Dunlop, R., and Wilson, G., "Frequency Actuated Load Shedding and Restoration, Part I - Philosophy," IEEE Transactions on Power App. Syst, Vols. PAS-90, no. No. 4, p. 1452-1459, July 1971.

[32] Terzija, V. V., "Adaptive Under-Frequency Load Sheddig Based on the Magnitude of the Disturbance Estimation," IEEE transactions on Power Systems, vol. 21, no. No. 3, pp. 1260-1266, 2006. 